\title{
PHOTOLUMINESCENCE SPECTRA OF MESFET AND HEMT
}

\author{
P. CONTI \\ CSELT-Centro Studi e Laboratori Telecomunicazioni S.p.A., Via G. Reiss Romoli 274, 10148 \\ Torino, Italy \\ (Received June 4, 1994; in final form June 21, 1994)
}

Photoluminescence spectroscopy has been employed in previous studies of semiconductor quantum wells and of buried interfaces in heterostructures. Nevertheless, the low amplitude of the signals collected, and the experimental difficulties, have limited the analyses to samples made on purpose.

On the contrary, in this work, the analyses at room temperature and at $4 \mathrm{~K}$ of a commercial MESFET and of a commercial HEMT are presented. With the performed experiments, new informations about the composition of these components were achieved; in particular signals from deep levels and from the $\mathrm{Cr}$ states of the HEMT substrate were detected.

After further studies on the shape of the spectra, the photoluminescence could probably be employed in reliability assessments to show the modifications in the semiconductor layer composition and in the shape of the heterostructure's surfaces of single devices.

\section{INTRODUCTION}

To build heterostructure devices of desired performances, the physical properties of the heterostructures at semiconductors interfaces must be known as well as their relations with the electrical characteristics of devices. However, to achieve this knowledge is a very difficult task, and it is complex even to understand how an heterostructure, grown by MBE or MOCVD in known conditions, has been built.

Cathodoluminescence and photoluminescence were employed for this purpose instead of the usual analysis techniques. The spectra generated by incident radiation from the semiconductor layers and from their interfaces have been detected and the problem has become to describe the connections between the shape of these spectra and the microscopic structure, and the chemical properties of both the semiconductor layers and their interfaces.

Photoluminescence (PL) had previously been employed to better understand the band structure of quantum wells [1] and quantum dots [2]; to measure the transitions energies between confined electron states in InAs/GaAs quantum wells [3] and to obtain the exciton binding and localization energies in InGaAs/GaAs [4]. PL proved to be useful also in the calculation of the surface state distribution and recombination velocities in InP [5] and GaAs [6] surfaces. In lattice matched and in strained GaInAs/AlInAs HEMT structures, the Fermi energy and the electron sheet concentration were deduced [7] and, with photoluminescence experiments, informations about the crystalline quality of AlGaAs/InGaAs/GaAs quan- 
tum wells were obtained and the sheet carrier density and the mobility were calculated [8].

In this paper, after a brief review of previous PL experiments on $\mathrm{AlGaAs} / \mathrm{GaAs}$ quantum wells (QW) and on HBTs (Heterostructure Bipolar Transistors) $[9,10$, $12,13,14]$, the results of the analyses at room temperature and at $4 \mathrm{~K}$ on a GaAs MESFET and on a AlGaAs/GaAs HEMT are presented.

\section{PHOTOLUMINESCENCE SPECTRA OF QWs AND HBTs}

Photoluminescence spectra were executed to study the chemical and crystallographic disorder as a function of the interruption time between the growth of the GaAs layer and the AlGaAs layer in QWs [9]. A He-Ne laser $(\lambda=632 \mathrm{~nm})$ with power density of $0.9 \mathrm{~W} / \mathrm{cm}^{2}$ was used. The PL signal was collected by a monochromator with linear dispersion of $1.25 \mathrm{~nm} / \mathrm{mm}$ and detected with a photomultiplier (RCA 31034A-02). The spectral resolution was between $0.06 \mathrm{~nm}$ and $0.3 \mathrm{~nm}$.

Samples examined were 10 layer QWs realized as shown in figure 1 . The GaAs layers were p-doped with $\mathrm{C}$ atoms with $8.10^{13} \mathrm{~cm}^{-3}$ density. The PL spectra of these samples are shown in figures 2, 3 and 4 as a function of the temperature and of the growth interruption time. A relationship between $\mathrm{QW}$ width and lattice constant was discovered and, from the PL peaks shapes, the formation of islands one monolayer in height at the AlGaAs/GaAs interface, realized with $30 \mathrm{~s}$ of interruption growth, was foreseen [9]. These islands were also imaged by using cathodoluminescence with the spectrometer centered on the peak of highest emission [10]. The shapes of the peaks were also obtained with a theoretical model, and the two peaks at the low energy side of the main peak in figure 3 were shown to be generated by the recombination between free electrons and localized $\mathrm{C}$ acceptor atoms. Their density has two maxima; one at the interface $\left(\mathrm{e}, \mathrm{A}_{\mathrm{i}}{ }^{\circ}\right)$ and the other in the center of the quantum well $\left(\mathrm{e}, \mathrm{A}_{\mathrm{c}}{ }^{\circ}\right)[11]$.

PL spectra were obtained also for heterostructure bipolar transistors (HBT), the origin of every signal was identified, and the photoluminescence results were correlated with transistor's performances [12]. One of the most important results was the discovery of a new signal originated from the heterojunction $\mathrm{p}^{+} \mathrm{GaAs} / \mathrm{n}$ AlGaAs.

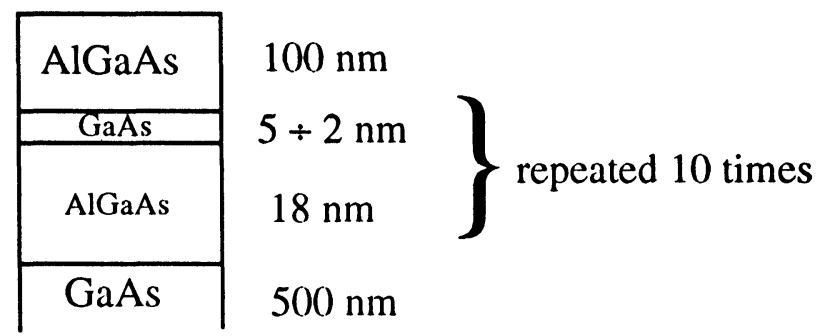

FIGURE 1 Ten layers AIGaAs/GaAs quantum well. 


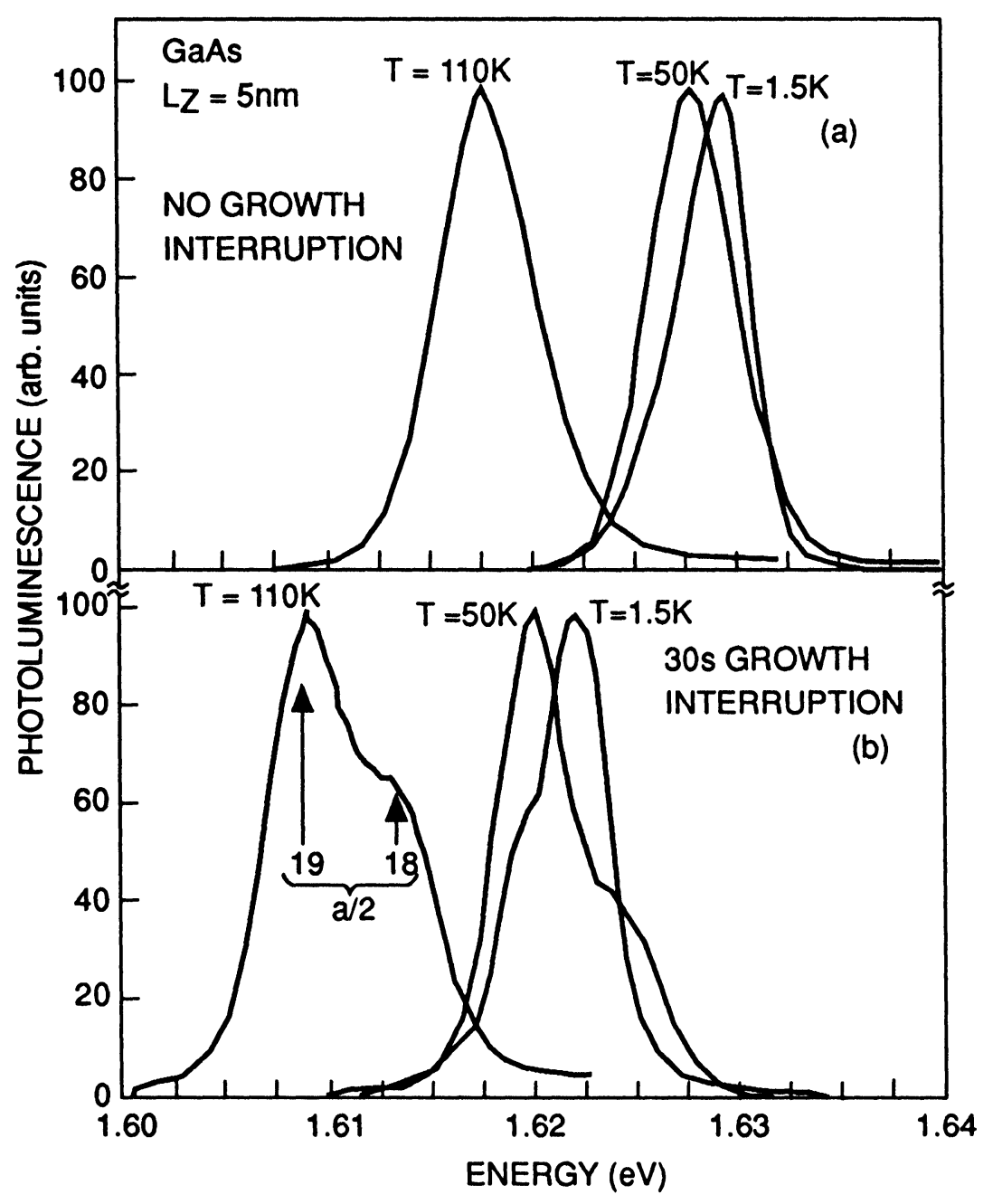

FIGURE 2 Photoluminescence of a $5 \mathrm{~nm} \mathrm{QW}$ as a function of temperature. a) Without growth interruption. b) With $30 \mathrm{~s}$ growth interruption. (From Ref. [9])

In these experiments, an $\operatorname{Ar}(\lambda=514.5 \mathrm{~nm})$ laser was used with $400 \mu \mathrm{m}$ of diameter spot. The temperature was $4.2 \mathrm{~K}$. The PL signal was analyzed by a Spex monochromator and detected by a photomultiplier (Hamamatsu HTRV 1767).

The typical band diagram of the tested HBTs is shown in figure 5.

To correctly identify the origin of the structures in the HBTs spectra, some samples of GaAs doped with Si (Fig. 7) and Be (Fig. 8), and of AlGaAs doped with Si (Fig. 9) were also examined at different doping concentrations. By comparison between these spectra and the HBTs spectra of figure 6 , the origin of the structures in the HBTs spectra could be identified (Table 1). On the contrary, the h7 peak, around $850 \mathrm{~nm}$, was established to be generated by the electron transitions 


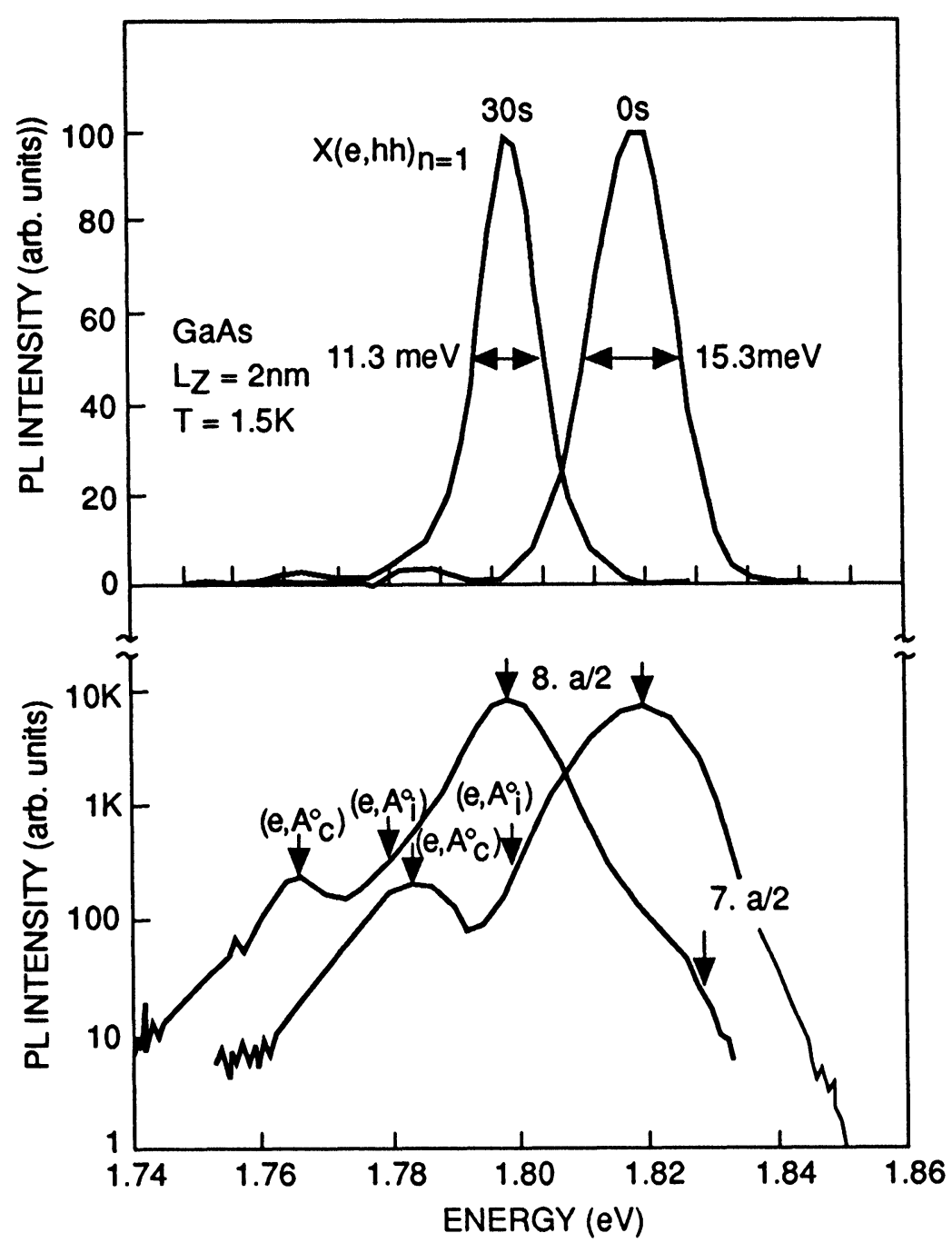

FIGURE $31.5 \mathrm{~K}$ photoluminescence of a $2 \mathrm{~nm} \mathrm{QW}$ without and with $30 \mathrm{~s}$ growth interruption in linear and logarithmic scales. (From Ref. [9])

between the two dimensional electron gas 2-DEG at the heterojunction $\mathrm{n}$ AlGaAs/ $\mathrm{p}^{+} \mathrm{GaAs}$ and the acceptor levels near the valence band [12].

Similar spectra were obtained by cathodoluminescence, and the semiconductor layers of the HBTs were photographed [13]. The cathodoluminescence results had also practical application in the validation of the insulation process of HBTs by B and $\mathrm{H}$ atoms and in the definition of the active regions of devices.

Another possible application of photoluminescence is in the quality control of the HBTs structure before device processing [14]. 


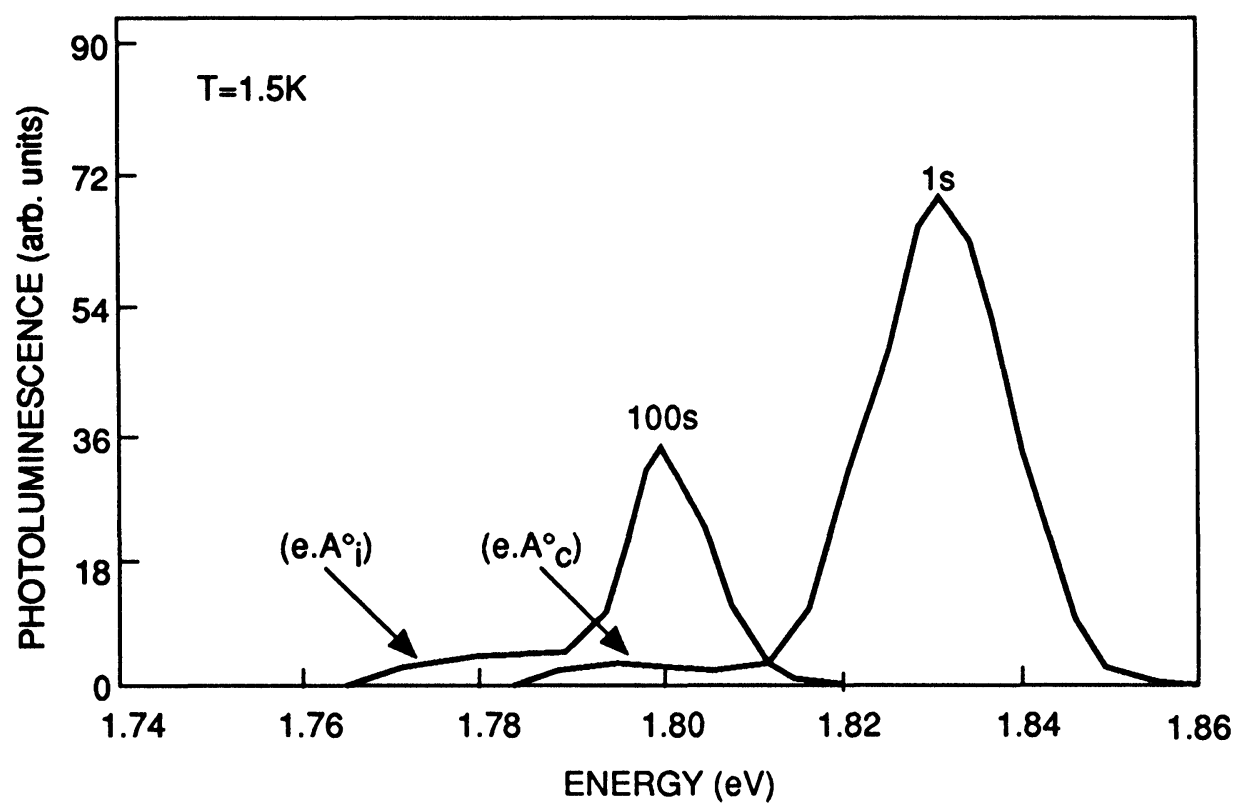

FIGURE $42 \mathrm{~nm}$ QW photoluminescence with $1 \mathrm{~s}$ and $100 \mathrm{~s}$ growth interruption times. (From Ref. [9])
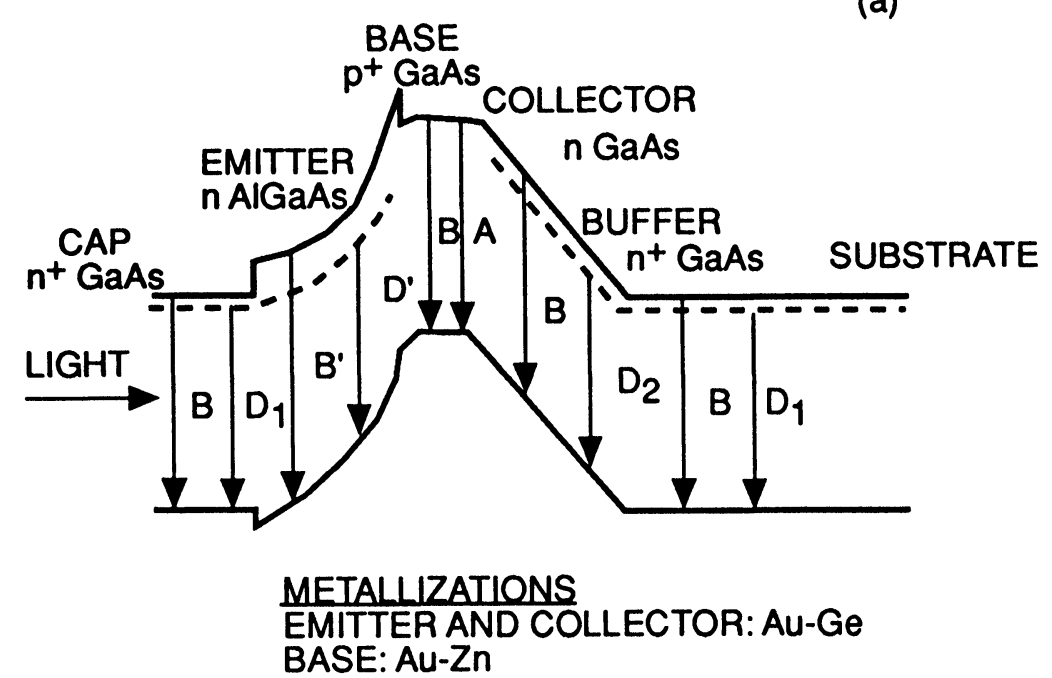

FIGURE 5 Band diagram of an HBT. 


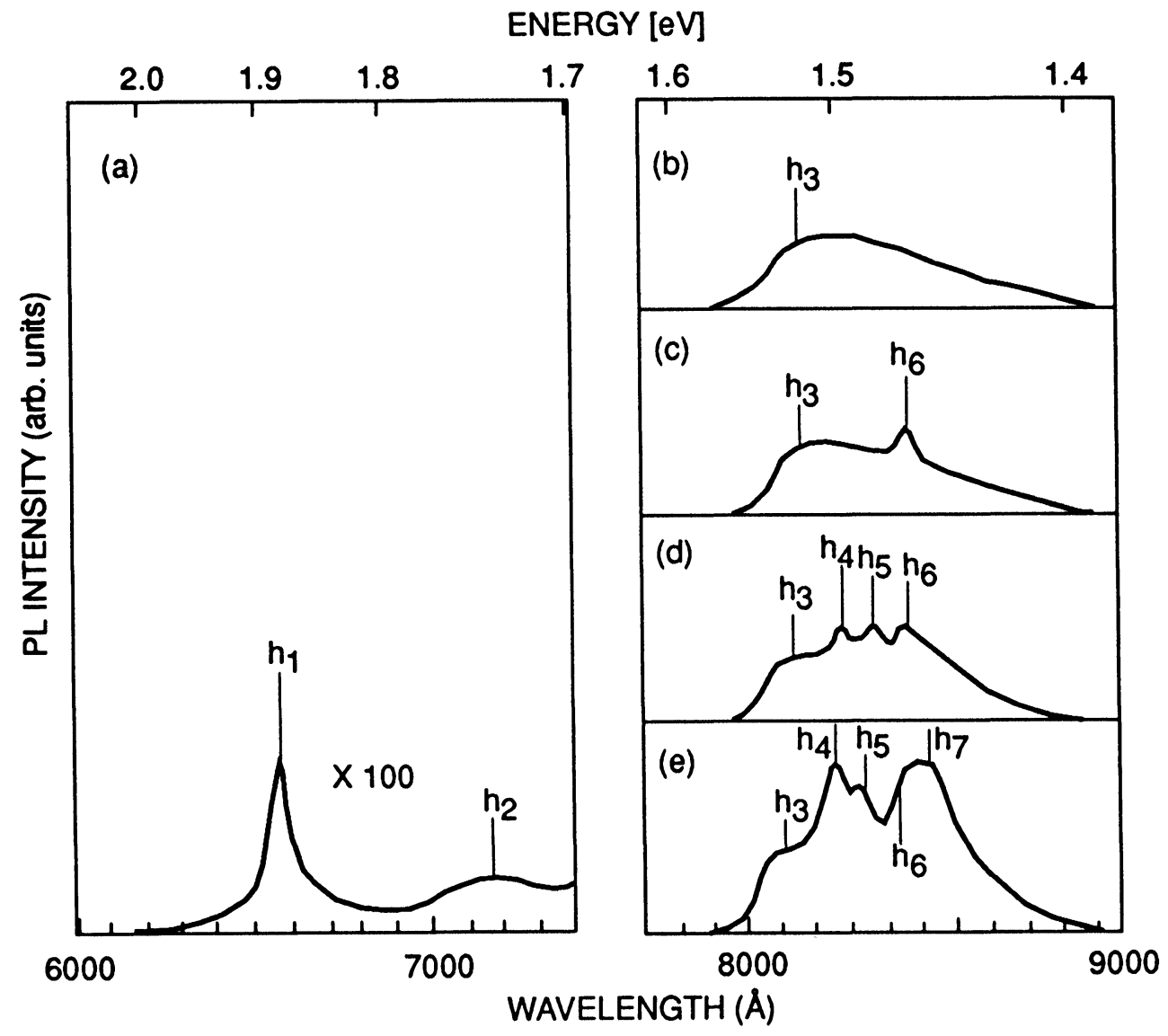

FIGURE 6 Photoluminescence spectrum of different HBTs. (From Ref. [12])

\section{PHOTOLUMINESCENCE OF MESFET AND HEMT}

The photoluminescence spectra of the GaAs MESFET of figure 10 and of the $\mathrm{AlGaAs} / \mathrm{GaAs}$ HEMT of figure 11 were obtained at room temperature and at 4 $\mathrm{K}$. Both these devices are low power and low noise transistors whose reliability was studied in previous works $[16,17,18]$.

\section{ROOM TEMPERATURE SPECTRA}

\section{Experimental Set up}

In the room temperature measurements, an $\operatorname{Ar}(\lambda=514 \mathrm{~nm})$ laser and a monochromator were used. The sample was mounted on a micrometric centering set up, and a Si detector and a lock-in amplifier were used to obtain the spectra. The wavelength resolution of this experimental set-up was $2-3 \mathrm{~nm}$ with the mono- 


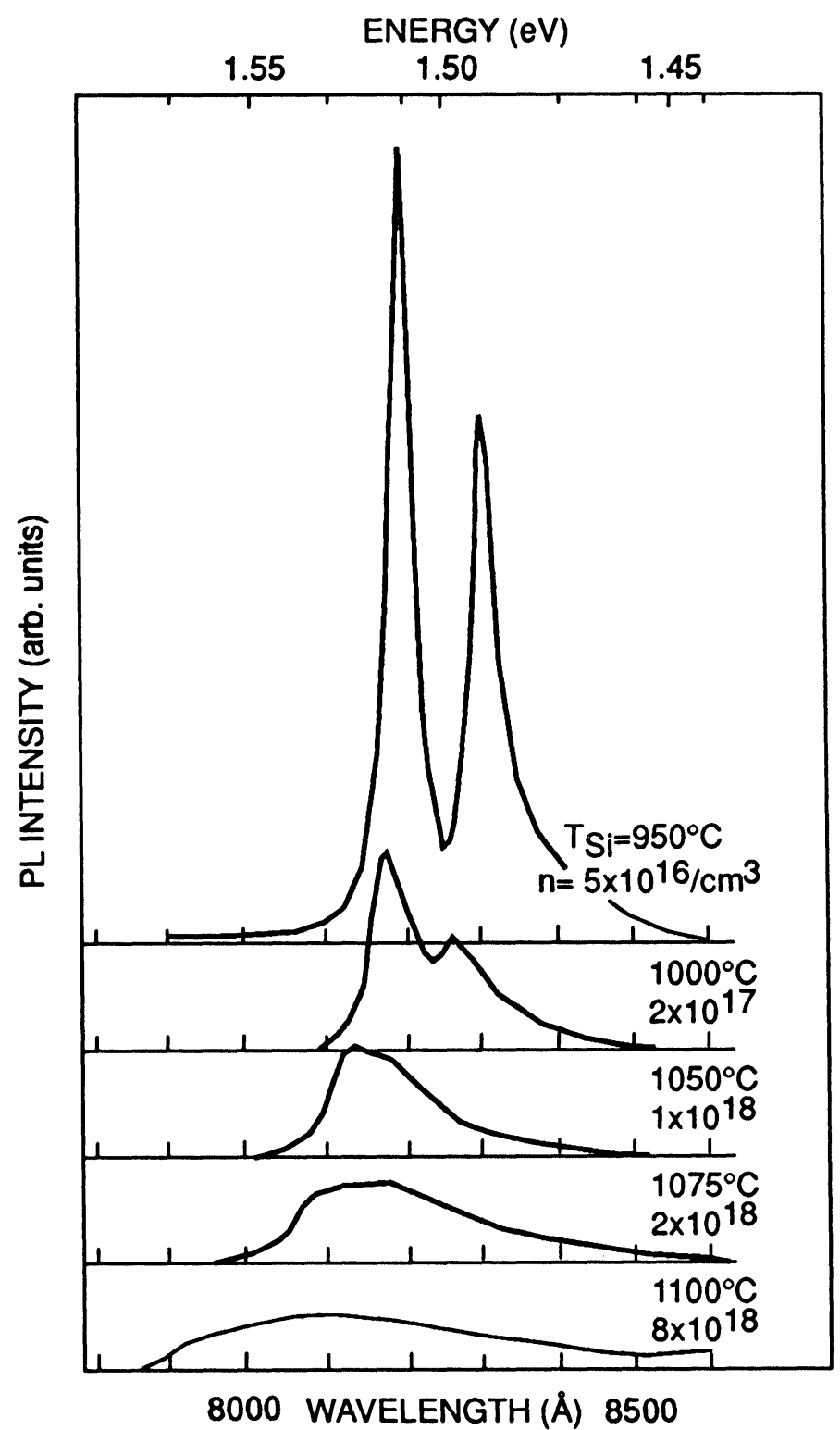

FIGURE 7 Photoluminescence of GaAs grown by $\mathrm{MBE}$ at $6(0))^{\circ} \mathrm{C}$ and doped with Si. (From Ref. [12])

chromator slits $2 \mathrm{~mm}$ opened. Spot diameter of the light on the sample was about $300 \mu \mathrm{m}$. A Si detector was used instead of a $\mathrm{Ge}$ one because of its higher responsivity and lower noise in the region of emission of the analyzed devices.

Components were demetallized before examination to expose the semiconductor to laser light. 


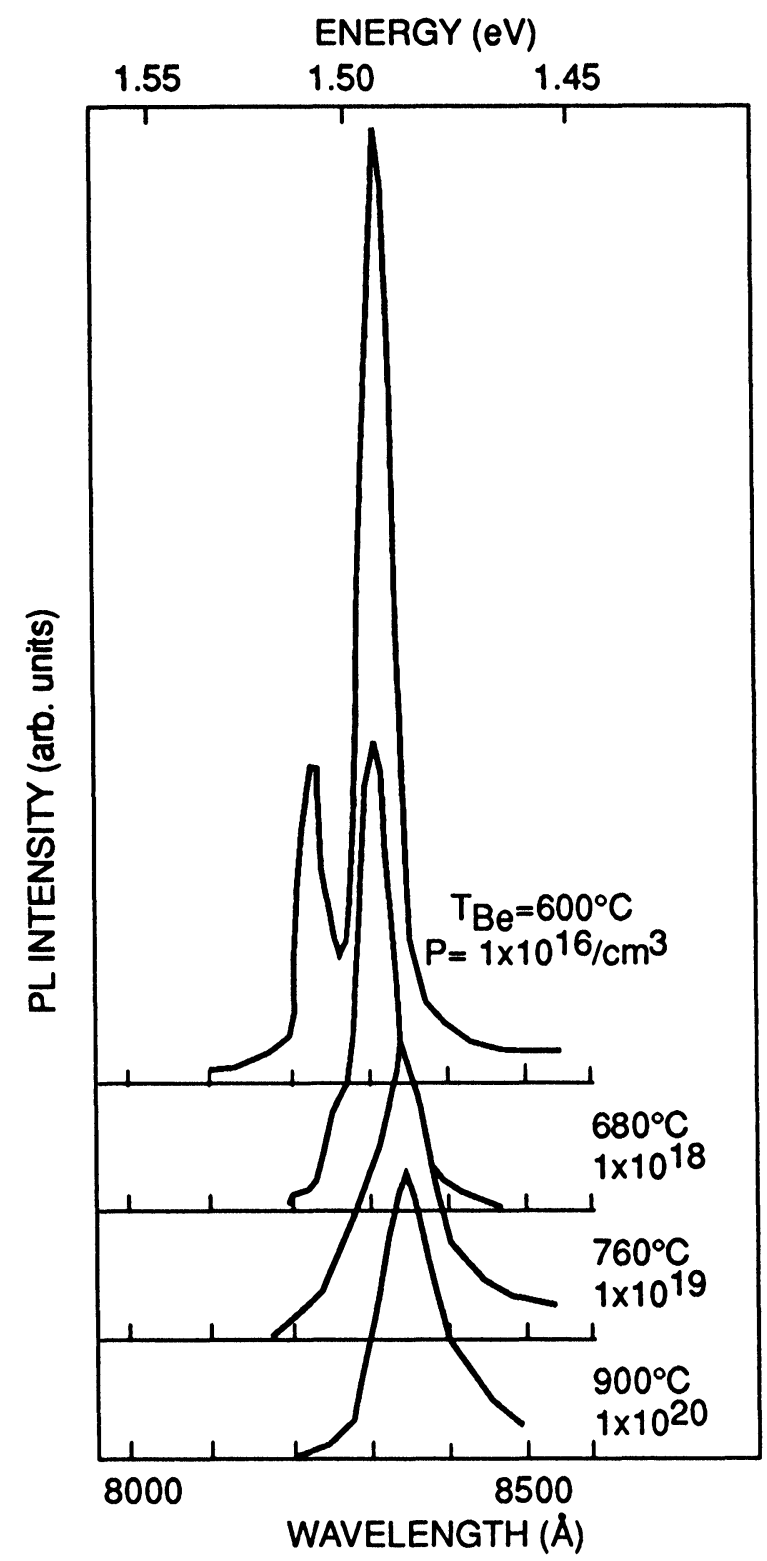

FIGURE 8 Photoluminescence of GaAs grown by $\mathrm{MBE}$ at $600^{\circ} \mathrm{C}$ and doped with Be. (From Ref. [12])

\section{Origin of Spectra Structures}

The spectrum of the MESFET of figure 10 [15], obtained with a laser power of $700 \mathrm{~mW}$, is shown in figure 12 . The peaks and the structures indicated with the arrows on the spectrum were identified at the corresponding wavelengths reported in Table 2. This spectrum extends below $780 \mathrm{~nm}$ and above $860 \mathrm{~nm}$, so that it was 


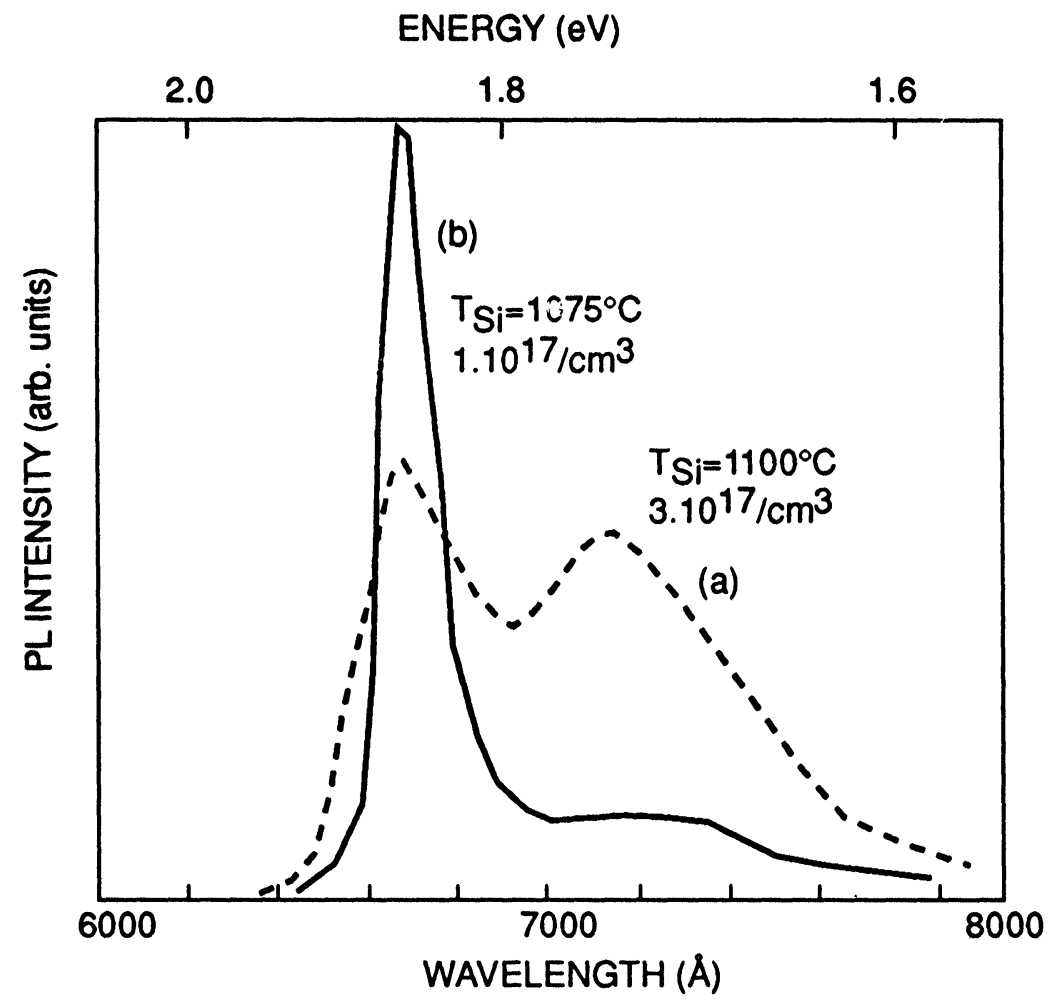

FIGURE 9 Photoluminescence of $\mathrm{AlGaAs}$ grown by $\mathrm{MBE}$ at $600^{\circ} \mathrm{C}$ and doped with Si. (From Ref. [12])

TABLE I

Photoluminescence structures in the HBTs spectra and layers of origin.

\begin{tabular}{|c|c|c|}
\hline Peak & Wavelength & Layers of peaks origin \\
\hline h1 & $660 \mathrm{~nm}$ & n AlGaAs - Emitter. \\
\hline h2 & $700+720 \mathrm{~nm}$ & n AlGaAs - Emitter. Peak dependent on $\mathrm{Si}$ \\
\hline h3 & $790 \div 860 \mathrm{~nm}$ & $\mathrm{n}+\mathrm{GaAs}-\mathrm{Cap}$ layer and Buffer. \\
\hline h4 & $815+820 \mathrm{~nm}$ & n GaAs - Collector. \\
\hline h5 & $825+831.5 \mathrm{~nm}$ & n GaAs - Collector. Peak dependent on $\mathrm{Si}$ \\
\hline h6 & $832.5 \div 840 \mathrm{~nm}$ & $\begin{array}{l}\text { concentration. } \\
\mathrm{p}+\mathrm{GaAs}-\mathrm{Base}\end{array}$ \\
\hline h7 & $\begin{array}{l}850 \mathrm{~nm} \\
(\text { Plaser }=30 \mathrm{~mW})\end{array}$ & $\begin{array}{l}\text { Peak characteristic of the } \mathrm{n} A \mathrm{lGaAs} / \mathrm{p}+\mathrm{GaAs} \\
\text { heterostructure. }\end{array}$ \\
\hline
\end{tabular}



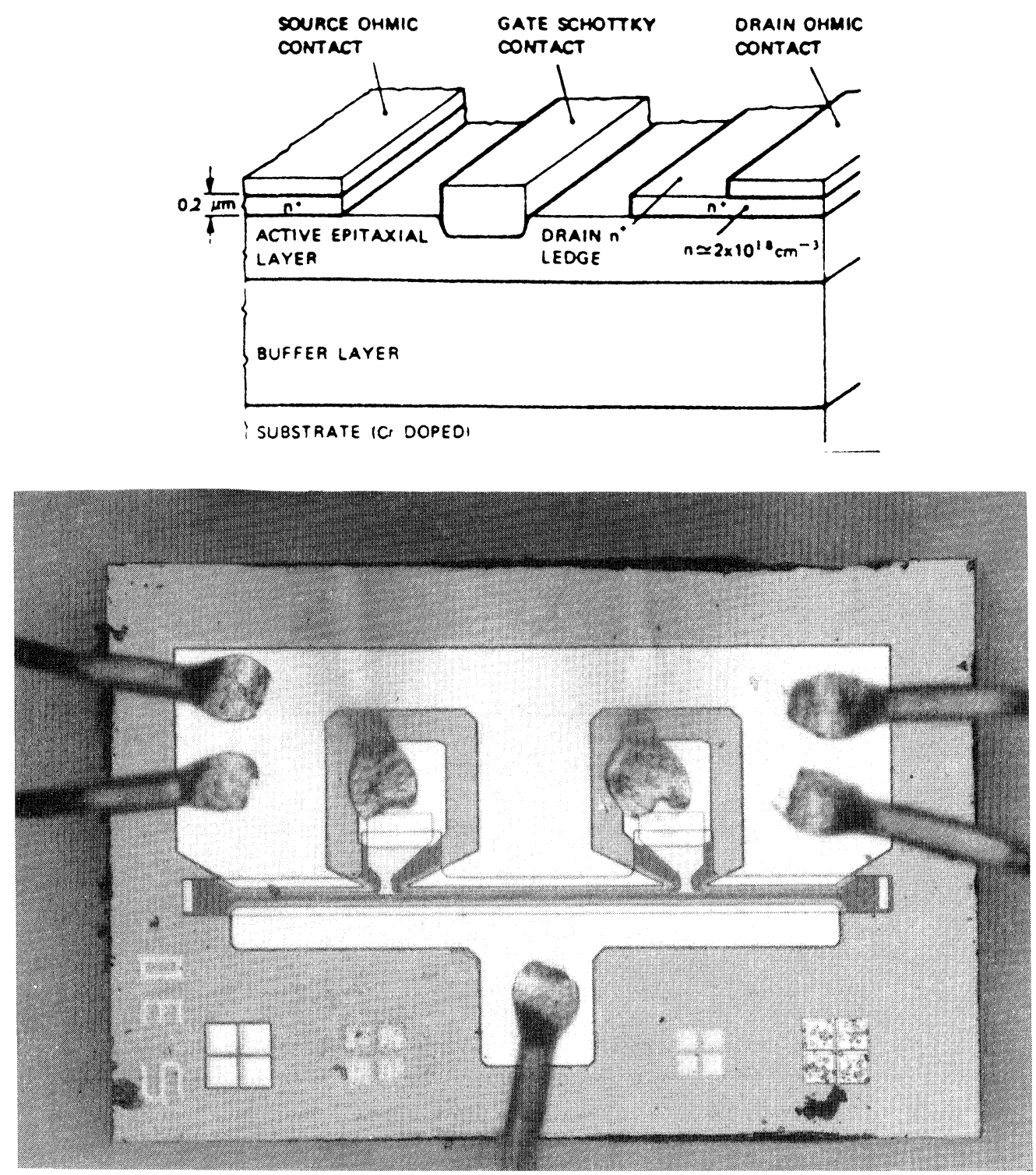

FIGURE 10 MESFET employed in photoluminescence analyses.

possible to detect the large peak at $915 \mathrm{~nm}$ and its shoulders at $880 \mathrm{~nm}$ and at 930 $\mathrm{nm}$ that could not be acquired in the previous works (Fig. 7 [12]). Comparing the MESFET spectrum to figure 7 and to the data of Table 1 (peaks h4 and h5), peaks a3 and a 4 were put in correspondence with the emission from the active $n$ GaAs layer of the component. With similar considerations, the origin of peak a2 was identified in the highly doped $\mathrm{n}^{+}$GaAs layers interposed between the active layer and the drain and source ohmic contacts. 

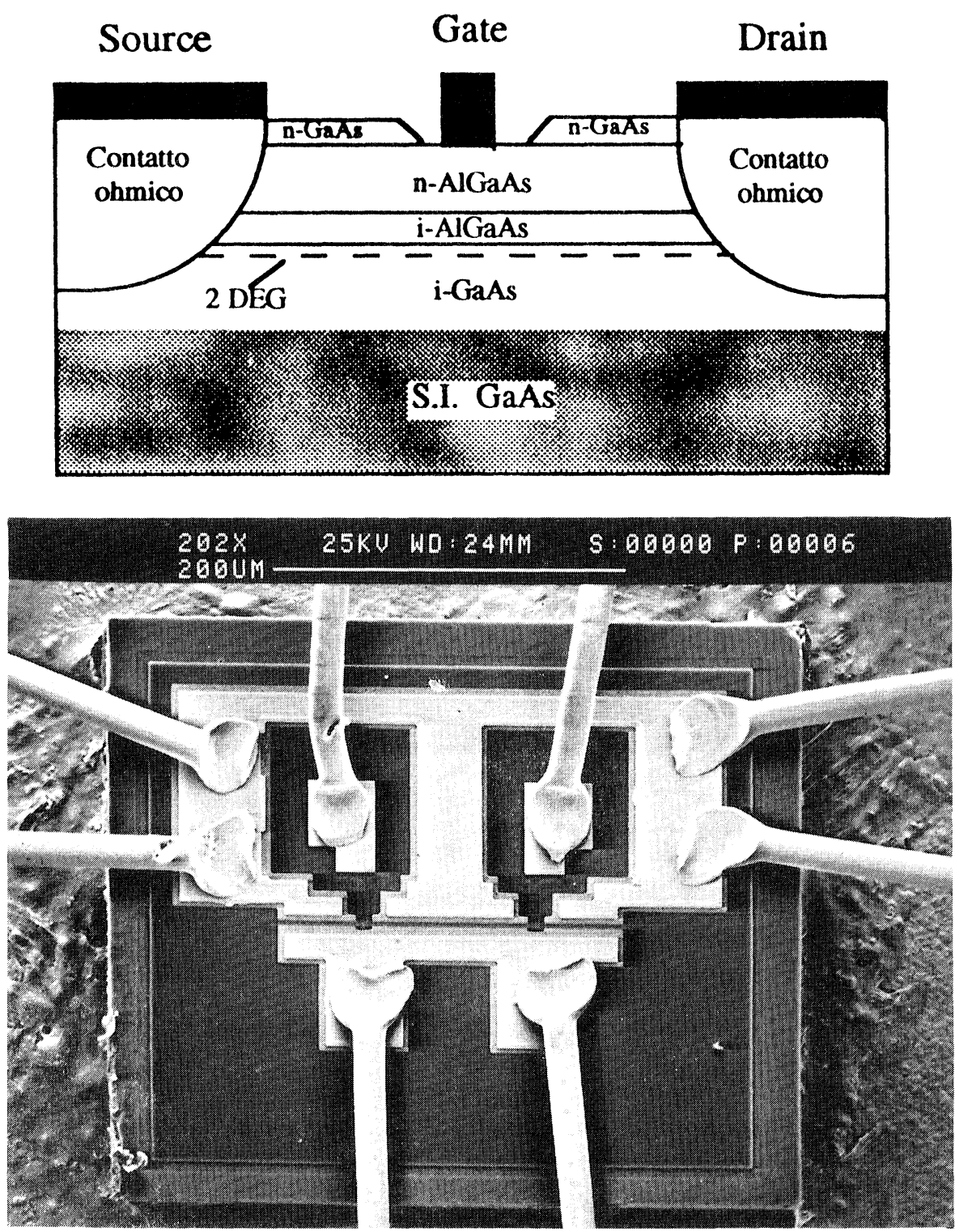

FIGURE 11 HEMT employed in photoluminescence analyses.

PL spectra of the HEMT were also obtained. These are shown in figures 13, 14, and 15. The main structures of these spectra are indicated with arrows and reported in Table 3 . The peaks b1 and b3, by comparison with figure 9 and considering the different experimental conditions, were related to the emission from the doped $\mathrm{n}^{+}$AlGaAs layer.

In previous experiments [12], an important relation between the shape of the AlGaAs peaks and the current gain $\beta$ of HBTs was discovered. In particular, an 


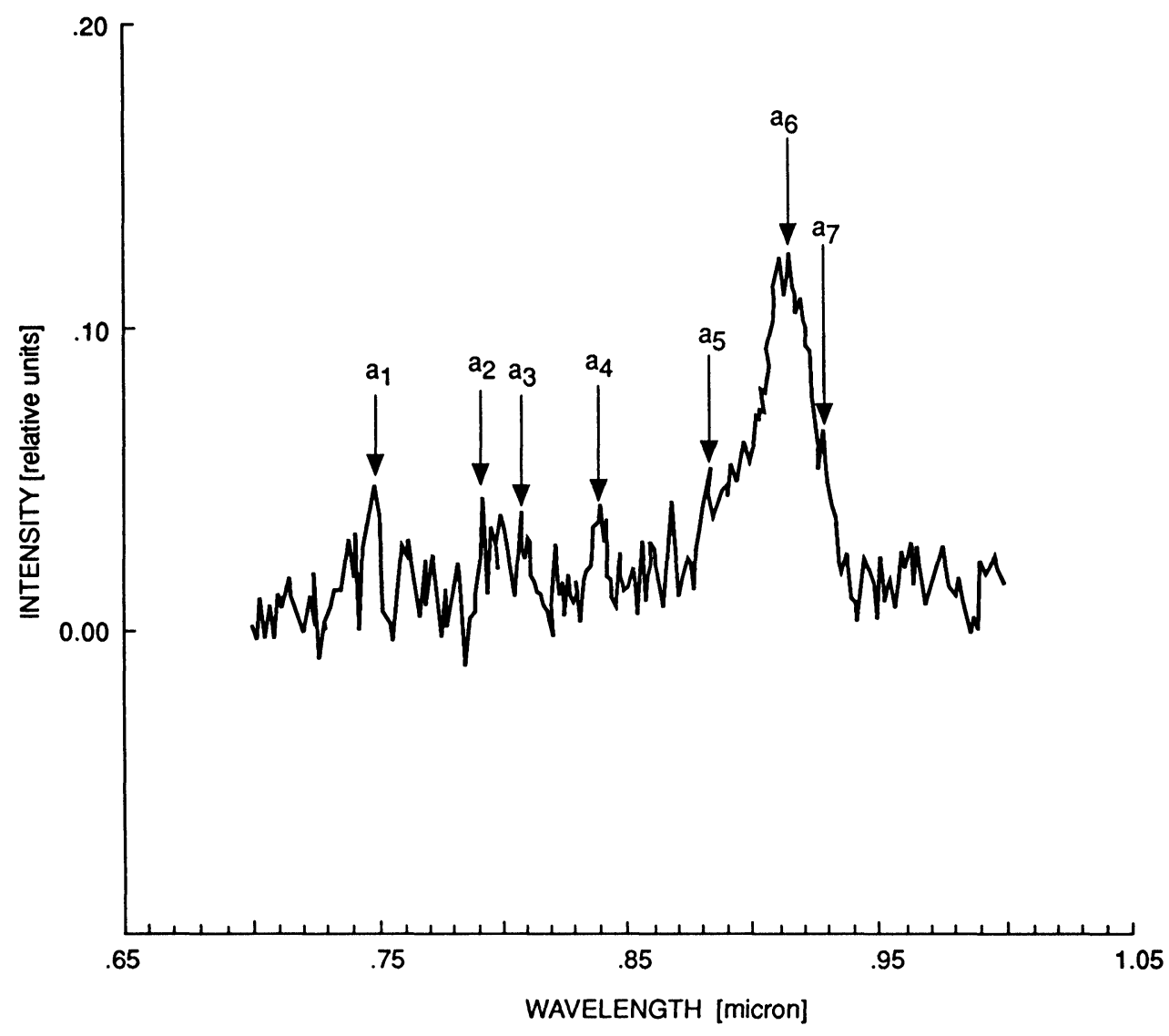

Peak wavelength: .915 micron

FWHM: $31.0 \mathrm{~nm}$

FIGURE 12 Photoluminescence spectrum of the MESFET (Slits $2 \mathrm{~mm}$ opened).

TABLE II

Photoluminescence structures in the MESFET spectrum and layers of origin.

\begin{tabular}{|c|c|c|}
\hline \multicolumn{2}{|c|}{ MESFET } \\
\hline Peak & Wavelength & Layers of peaks origin \\
\hline a1 & $750 \mathrm{~nm}$ & \\
a2 & $792.5 \mathrm{~nm}$ & $\mathrm{n}+$ GaAs - Ohmic contacts. \\
a3 & $810 \mathrm{~nm}$ & n GaAs - Active layer. \\
a4 & $840 \mathrm{~nm}$ & n GaAs - Active layer. \\
a5 & $880 \mathrm{~nm}$ & \\
a6 & $915 \mathrm{~nm}$ & \\
a7 & $930 \mathrm{~nm}$ & \\
\hline
\end{tabular}




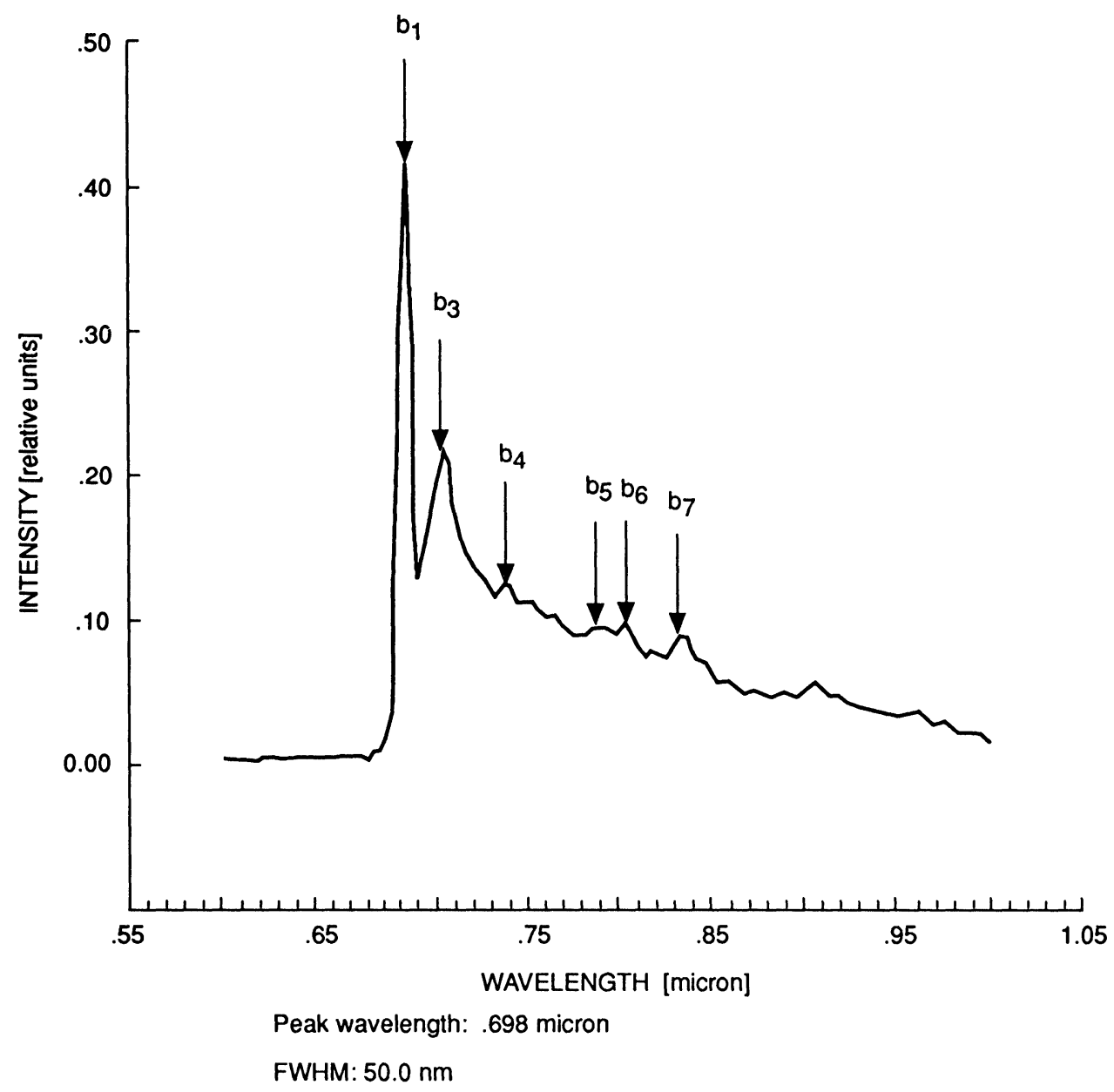

FIGURE 13 Photoluminescence spectrum of the HEMT. (Slits $2 \mathrm{~mm}$ opened.)

increase of the main peak intensity and a decrease of its FWHM width was shown to indicate a higher $\beta$ transistor. The same result should be true also for HEMTs transconductance because the HEMTs are devices whose electrical performances relay essentially on the heterojunction shape, and then on the characteristics of the AlGaAs layer.

The wavelengths of peaks a1, b4; a 2, b5; a3, b6; a4, b7 are equal (Table 3 and 2 ), so that peaks $b 4, b 6$ and $b 7$ were related to the undoped GaAs layer. The other peak, b5, could be generated by the $\mathrm{n}^{+}$GaAs layers that were not detected with other analysis techniques $[17,18]$ but that probably were located at the ohmic contacts to ensure a better electric contact between the AlGaAs and the source and the drain. Another possibility is that b5 derives from the $\mathrm{n}^{+}$layers at the interface $\mathrm{AlGaAs} / \mathrm{GaAs}$ placed at gate edges [19].

Equal peak wavelengths of the doped GaAs layer of the MESFET and of the undoped GaAs HEMT layer can mean that at room temperature it is impossible 


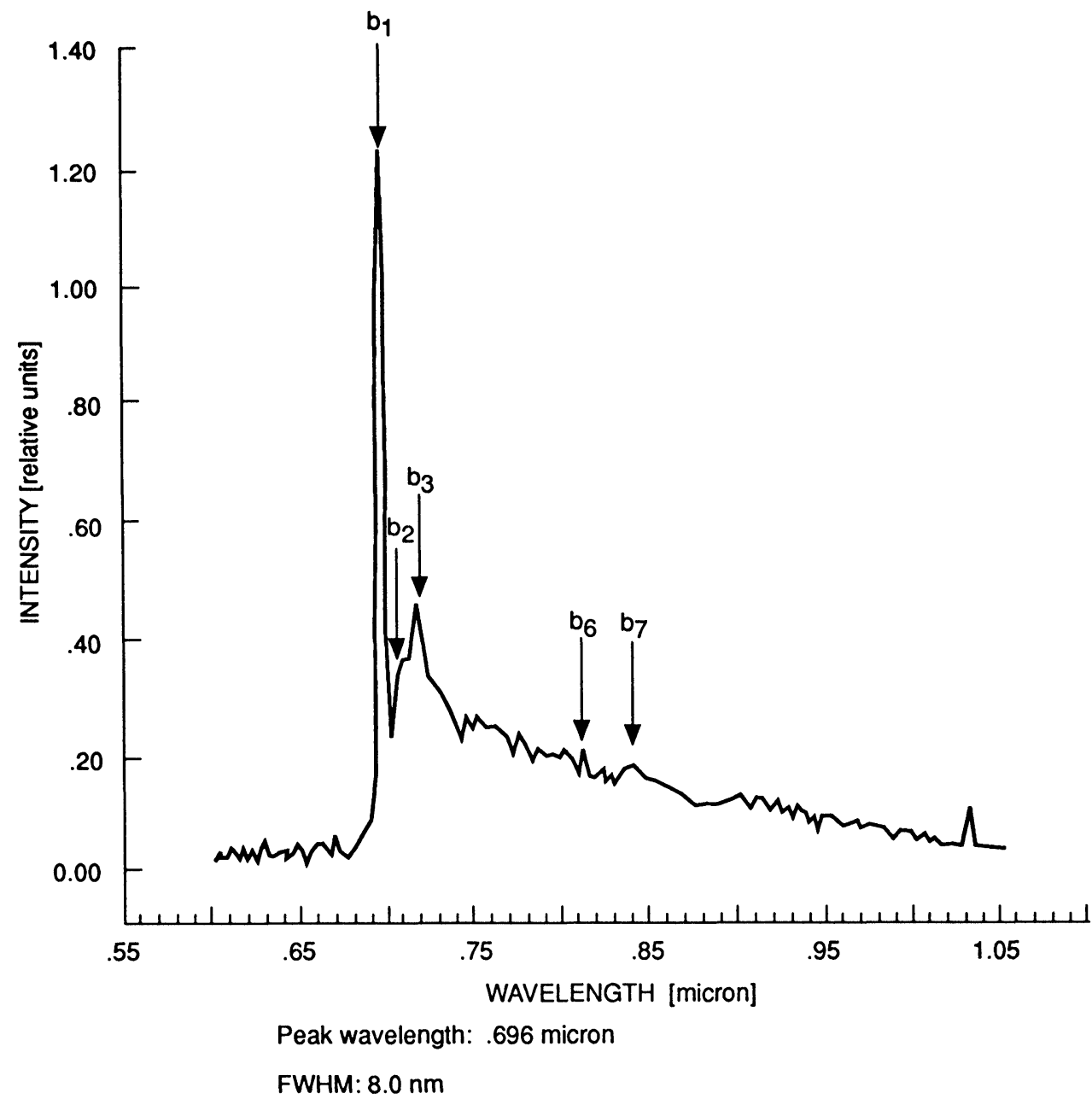

FIGURE 14 Photoluminescence spectrum of the HEMT. (Input slit: $1 \mathrm{~mm}$; output slit: $0.5 \mathrm{~mm}$.)

to appreciate the differences in the doping or, and perhaps more likely, that the presence of the 2-DEG at the interface AlGaAs/GaAs modifies the spectrum of undoped GaAs making it very similar to that of doped GaAs.

Structure b2, which was not detected in the examined literature (Fig. 7), could also be generated by the electron states at the interface of the heterojunction.

Finally, the similarities between the spectral structures of figures 3 and 4 , relative to the photoluminescence of $2 \mathrm{~nm}$ thick QWs, and the peaks b1 and b3 of the HEMT spectrum indicate that, reducing the QW thickness, electrons remain confined in a very thin layer that, as regards the photoluminescence, presents properties similar to those of a single interface 2-DEG. 


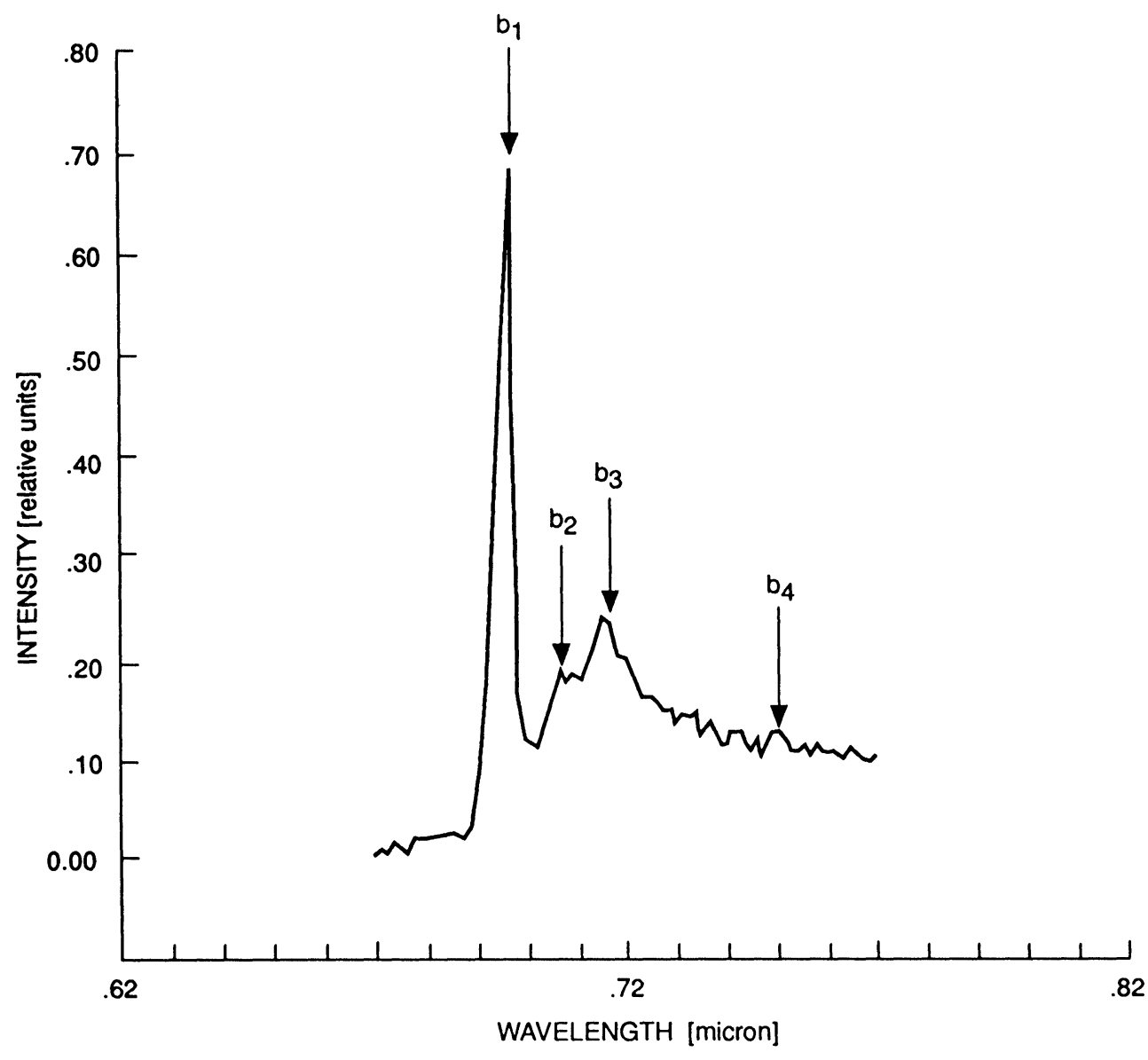

Peak wavelength: .696 micron

FWHM: $7.0 \mathrm{~nm}$

FIGURE 15 Particular of the low wavelengths region of the spectrum of Fig. 14.

\section{K SPECTRA}

\section{Experimental Apparatus}

The experimental apparatus for the measurements at $4 \mathrm{~K}$ was a Fourier transform BIORAD spectrometer. It mounted an Ar laser with a maximum power of $40 \mathrm{~mW}$ on a $1 \mathrm{~mm}$ diameter spot. A Ge detector was used. The sample was attached to a cryostat and cooled at liquid helium temperature.

\section{Origin of Spectral Structures}

The photoluminescence spectrum at $4 \mathrm{~K}$ of the HEMT of figure 11 is shown in figure 16. The PL signal was observed from $0.67 \mu \mathrm{m}$ to $1.67 \mu \mathrm{m}$. The region on 
TABLE III

Photoluminescence structures in the HEMT spectrum and layers of origin.

\begin{tabular}{|c|c|l|}
\hline \multicolumn{2}{|c|}{ HEMT } \\
\hline Peak & Wavelength & Layers of peaks origin \\
\hline b1 & $695 \mathrm{~nm}$ & $\mathrm{n}+$ AlGaAs - AlGaAs doped layer. \\
b2 & $708 \mathrm{~nm}$ & \\
b3 & $715 \mathrm{~nm}$ & n+ AlGaAs - AlGaAs doped layer. \\
b4 & $750 \mathrm{~nm}$ & $\begin{array}{l}\text { GaAs - Egual to the a1 peak of the MESFET. } \\
\text { n+ GaAs - Layers on the ohmic contacts or at } \\
\text { the gate sides of the heterostructure. } \\
\text { b5 }\end{array}$ \\
b6As - Active buffer layer. \\
b7
\end{tabular}

the right of the vertical dashed line is the portion of the spectrum detected also at room temperature and discussed previously. The PL signal was very noisy, and the identification of its structures very difficult. The low $\mathrm{S} / \mathrm{N}$ ratio was due to the low laser power on the spot, which in this case was of only $40 \mathrm{~mW}$, instead of the 700 $\mathrm{mW}$ employed in the room temperature measurements.

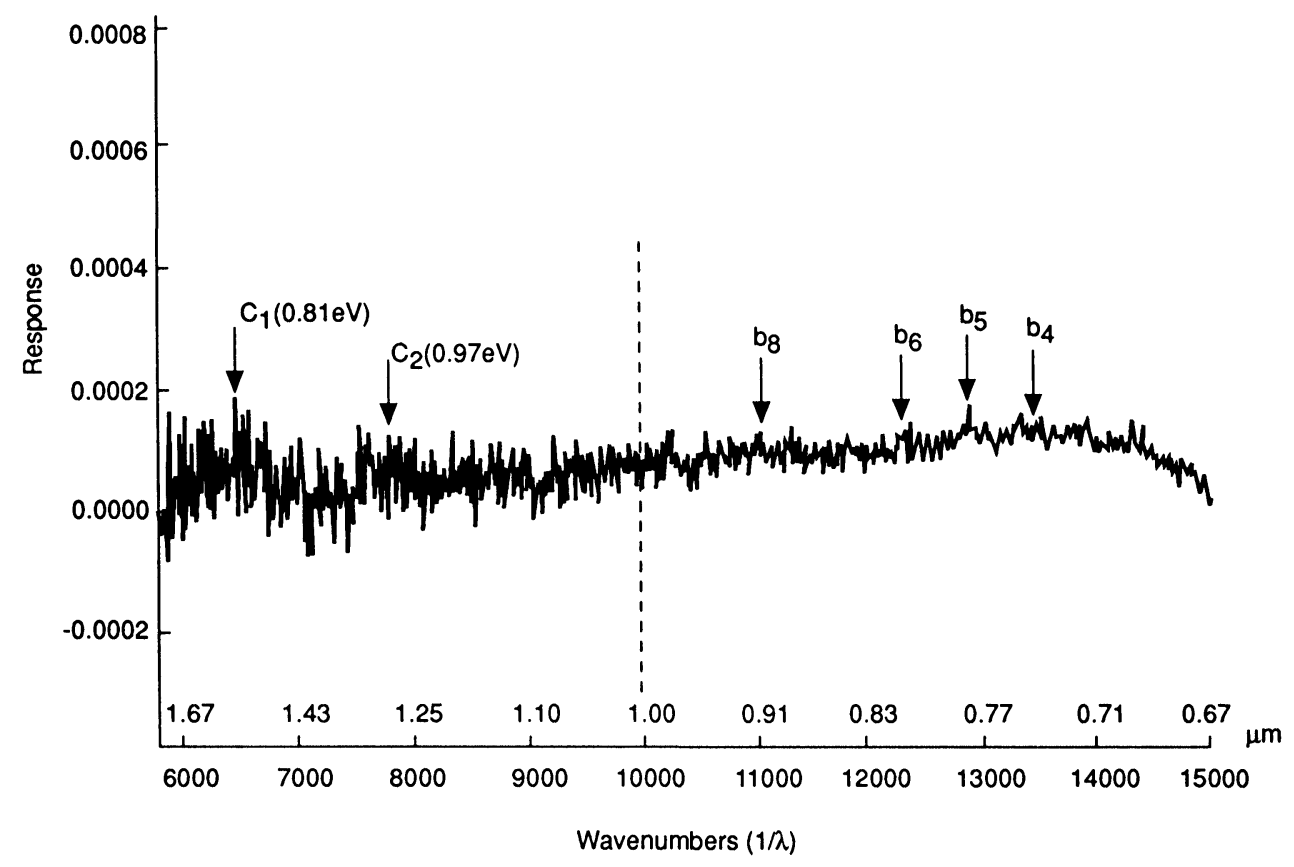

FIGURE 16 HEMT photoluminescence spectrum at $4 \mathrm{~K}$. 
In spite of these difficulties, some slight variations of the signal were indicated as spectrum singularities that turned to be at the same frequencies of the peaks already detected at room temperature (Tab. 3 and fig. 16) except the peak around $780 \mathrm{~nm}$, that was put in correspondence with peak b5 at room temperature that, at $4 \mathrm{~K}$, was supposed to have shifted toward lower wavelengths (Fig. 2).

Peaks from $\mathrm{n}^{+}$AlGaAs layer were not detected because, at these wavelengths, the responsivity of $\mathrm{Ge}$ detectors is low and the use of a Si detector, as was done in the room temperature measurements, would be better. In fact, at $1 \mu \mathrm{m}$, the responsivity of Ge detectors is about $0.2 \mathrm{~A} / \mathrm{W}$, while the responsivity of Si detectors is about $0.4-0.5 \mathrm{~A} / \mathrm{W}$.

Nevertheless, in the region of the spectrum between $1 \mu \mathrm{m}$ and $1.67 \mu \mathrm{m}$, two maxima were identified; $\mathrm{c} 1$ at $1.54 \mu \mathrm{m}(0.81 \mathrm{eV})$ and $\mathrm{c} 2$ at $1.28 \mu \mathrm{m}(0.97 \mathrm{eV})$. They probably originate as follows: $\mathrm{c} 1$ from the transitions between the conduction band and the deep level EL2 in the GaAs layer, and c2 from the transitions to the light holes HL1 states of the $\mathrm{Cr}$ atoms with which the GaAs substrate was probably doped to make it semi-insulating [20].

\section{EXPERIMENTAL PROBLEMS WITH SINGLE COMPONENTS}

The centering of the HEMT under laser light turned up to be a very difficult operation. In particular, in the measurements at room temperature, many attempts had to be made before detecting a signal of sufficient amplitude. The problem is that the HEMT is very small $(395 \mu \mathrm{m} \times 350 \mu \mathrm{m})$ and, in addition, the $200 \mu \mathrm{m}$ long region in which the AlGaAs was deposited has a width of only a few microns, so that it is an extremely difficult task to put it under the spot without the help of a microscope.

Another problem in the measurements at room temperature is the high laser power needed; in excess of $900 \mathrm{~W} / \mathrm{cm}^{2}$. With such high power densities, devices warm up and, if the irradiation lasts for too long, they can be damaged. Due to heating, the measured spectra cannot be acquired at room temperature but rather at higher temperatures.

Even in the measurements at $4 \mathrm{~K}$, sample centering was not easy and also with $40 \mathrm{~mW}$, the maximum laser power, a good signal-to-noise ratio could not be achieved.

The problem of power density arises because semiconductor layers of single devices are small and thin; their dimensions and their area are too small to generate a signal of sufficient amplitude unless using high laser power densities. Better photoluminescence spectra could probably be obtained employing a laser cofocal microscope modified to detect the photoluminescence signal and to cool the sample.

\section{METHOD TO IDENTIFY THE SPECTRAL STRUCTURES}

A method to identify the origin of the photoluminescence spectra structures of the heterostructure components consists of selectively removing, one by one, the sem- 
iconductor layers of the components [12]. After each step, photoluminescence spectrum is measured and the disappearance of some structures from the spectrum at the previous step indicates that those structures were generated by the removed layer.

Either plasma [21] or liquid [22] selective etching can be used to remove the semiconductor layers of the heterostructure devices.

\section{CONCLUSIONS}

Photoluminescence spectra of commercial MESFET and HEMT have been obtained at room temperature and at $4 \mathrm{~K}$ and some of the spectral structures of these components have been related to the GaAs and AlGaAs semiconductor layers (Table 2, 3 and fig. 16).

Also, two humps in the $4 \mathrm{~K}$ spectrum of the HEMT have been attributed to the deep level EL2 transitions, and to the Cr atoms levels transitions.

\section{ACKNOWLEDGMENTS}

I wish to thank Dr. C. Coriasso who performed the photoluminescence measurements at room temperature, and Dr. A. Antolini who performed the measurements at $4 \mathrm{~K}$.

Many thanks also to Dr. D. Campi for his advice and for his help in revising the paper.

\section{REFERENCES}

1. R.P. Schneider, Jr., B.W. Wessels, "Photoluminescence excitation spettroscopy of $\operatorname{InAs}_{0.67} \mathrm{P}_{0.33} /$ InP strained single quantum wells," J. of Electronic Materials 20(12), 1117-1123 (1991).

2. K. Brunner, U. Bockelmann et al., "Photoluminescence from single GaAs/AlGaAs quantum dot," Phys. Rew. Lett. 69(22), 3216-3219 (1992).

3. A. Esendzov, F.J. Grunthaner, et al., "Absorption and photoluminescence of ultrathin pseudomorphic InAs/GaAs quantum wells," Phys. Rev. B 43(18), 14574-14580 (1991).

4. M. Gal, Z.Y. Xu et al., "Exciton localization in $\mathrm{In}_{\mathrm{x}} \mathrm{Ga}_{1-\mathrm{x}} \mathrm{As} / \mathrm{GaAs}$ quantum wells observed by temperature-modulated photoluminescence," Phys. Rev. B 43(2), 1546-1550 (1991).

5. M. Ochiai, P. Sebestyen, D.L. Lile, "Interface state analysis using integrated room temperature gated photoluminescence," Electr. Lett. 29(6), 568-569 (1993).

6. T. Saitoh, H. Hasegawa, "Relationship among surface state distribution, recombination velocity and photoluminescence intensity on semiconductor surfaces," Appl. Surface Sci. 56-58, 94-99 (1992).

7. A. Tabata, T. Benyattou et al., "Characterization of lattice-matched and strained GaInAs/AlInAs HEMT structures by photoluminescence spettroscopy," Appl. Surf. Sci. 63, 182-186 (1993).

8. A. Dodabalapur, V.P. Kesan et al., "Photoluminescence and electroreflectance studies of modulation-doped pseudomorphic AlGaAs/GaAs quantum wells," J. of Electr. Materials 19(3), 265$270(1990)$.

9. D. Bimberg, D. Mars et al., "Structural changes of the interface, enhanced interface incorporation of acceptors, and luminescence efficiency degradation in GaAs quantum wells grown by molecular beam epitaxy upon growth interruption," J. Vac. Sci. Technol. B4(4), 1014-1021 (1986).

10. D. Bimberg, J. Christen et al., "Cathodoluminescence atomic scale images of monolayer islands at GaAs/GaAlAs interfaces," J. Vac. Sci. Technol. B5(4), 1191-1197 (1987).

11. W.T. Masselink, Yia-Chung Chang et al., "Acceptor spectra of AlGaAs-GaAs quantum wells in external fields: Electric, magnetic, and uniaxial stress," Physical Rew. B 32(8), 5190-5201 (1985).

12. Kazuo Eda, Masamori Inada, "Photoluminescence in AlGaAs/GaAs heterojunction bipolar transistors," J. Appl. Phys. 62(10), 4236-4243 (1987). 
13. C. Dubon, A.C. Papadopoulo et al, "Characterization of AlGaAs/GaAs heterojunction bipolar transistors and circuits by localized filtered low temperature cathodoluminescence," J. Appl. Phys. 66(6), 2603-2607 (1989).

14. T. Humer-Hager, H. Tews, "Photoluminescence in GaAs/AlGaAs heterostructure bipolar transistors: An investigation of the properties of Mg acceptor," J. Appl. Phys. 68(3), 1310-1317 (1990).

15. E. Pollino, Microelectronic Reliability (Artech House, Norwood, MA 1989) Vol. 2.

16. G. Clerico Titinet, E. Pollino, D. Riva, "Reliability of compound semiconductor microwave field effect devices: failure mechanisms and test methods," Proc. MIEL (1989).

17. P. Conti, L. Marchisio et al., "Performances and reliability of HEMTs: state of the art and experimental analysis," Microelectronics Reliab. 32(11), 1577-1583 (1992).

18. E. Arduino, R. Comitangelo et al. " "Storage tests and failure analyses on AlGaAs/GaAs HEMTs," Proc. ISTFA (1992).

19. H. Morkoc, H. Unlu, G. Ji, Principles and Technology of MODFETs (John Wiley \& Sons, 1991).

20. D.C. Look, Electrical characterization of GaAs materials and devices, (John Wiley \& Sons, 1989).

21. D.E. Ibbotson, D.L. Flamm, "Plasma etching for III-V compound devices," Solid State Technol., Part I 31(10), 77-79 (1988); Part II 31(11), 105-108 (1988).

22. C. Juang, K.J. Kuhn et al., "Selective etching of GaAs and AlGaAs with citric acid/hydrogen peroxide solutions," J. Vac. Sci. Technol. B8(5), 1122-1124 (1990). 

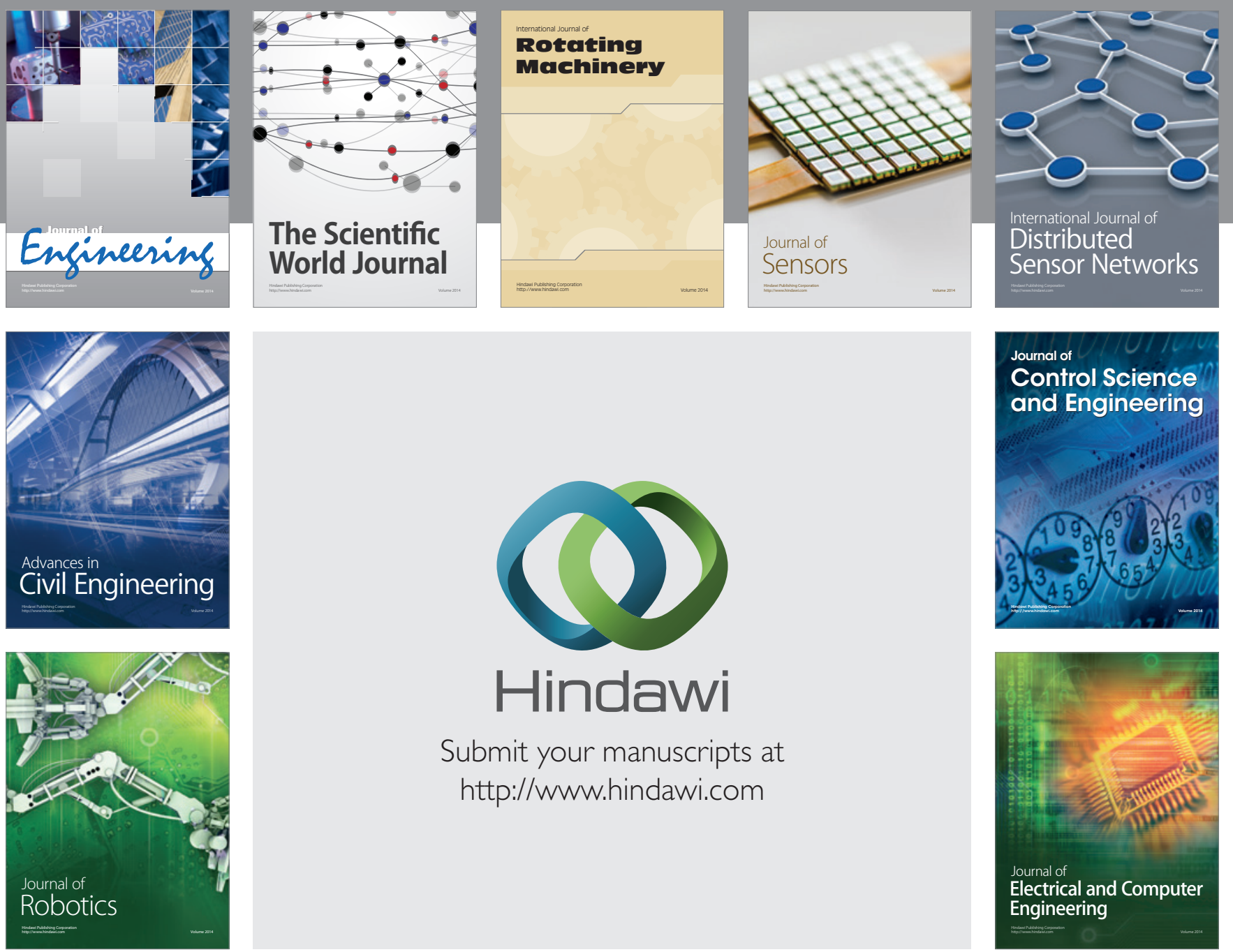

Submit your manuscripts at

http://www.hindawi.com
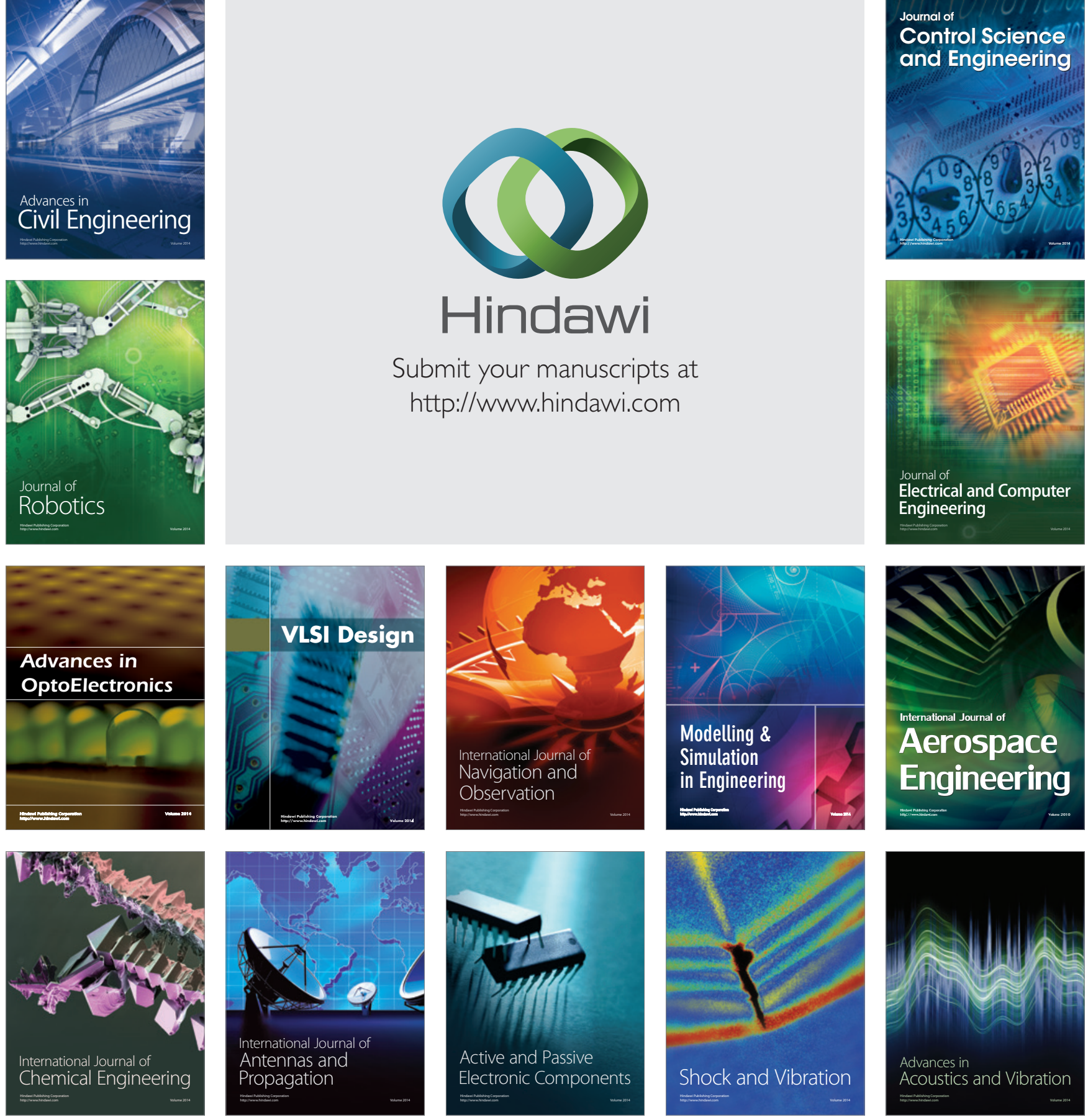